\title{
Gervaise et l'héroïne hardienne
}

\author{
D a n a C l into ll
}

En lisant L'Assommoir, on est frappé par des ressemblances entre Gervaise Coupeau et I'héroĩne typique de Thomas Hardy, surtout Tess of the D'Urbervilles. Evidemment les deux auteurs partagent quelques idées fondamentales sur $1 \mathrm{a}$ vie.

D'abord, tout lecteur de ces deux livres sent que ces deux héroînes auraient dû réussir dans la vie. Gervaise et Tess semblent toute gentillesse et honnêteté. Surtout au commencement du livre, I'héroĩne paraît cout de suite digne d'admiration par sa remarquable résistance à des circonstances peu favorables. Et instinctivement on pardonne aux femmes leur chute, car il semble naturel de perdre courage quand leur bonheur est menacé sans cesse par des forces adverses.

Et voilà un lien net qui rapproche Zola et Hardy. Leurs héroInes échouent à la fin à cause d'une fatalité imprévisible et non à cause de leurs propres défauts. Cela sous-entend que notre destinée nous est attribuée au moment de la naissance, et que nous ne pouvons rien faire pour changer sa direction. liardy ne cache guère cette conception de la fatalité: "Why was it that upon this beautiful feminine tissue, sensitive as gossamer, and practically blank as snow yet, there should have been traced such a coarse pattern as it was doomed to receive..." (p. 63). I1 faut faire une distinction cependant. Zola tient à l'idée d'hérédité; c'est-à-dire que Gervaise échoue parce que née dans une famille qui échouera toujours, ayant hérité des défauts ancestraux qui mènent définitivement à la failitte. Ce n'est donc pas tout le monde 
qui sera malheureux au fond. Les uns héritent des traits heureux qui les aident, les autres de malheureuses tendances. Hardy ne partage pas cette opinion. I1 reste toujours de 1 'avis que notre monde entier a été choisi parmi d'autres pour subir une fatalité malveillante. Tess est une créature destinée au malheur dans un monde Iui-même destiné au malheur. Elle déclare à son petit frère: "we be on a blighted star, and not a sound one "(p.24). I1 est évident que Tess et Gervaise sont toutes les deux prédestinées au malheur en dépit de leurs traits rédempteurs. En effet, c'est justement à cause de leur bonté extraordinaire qu'on se rend vivement compte du parti pris des deux auteurs. Une femme ordinaire qui échoue dans la vie provoquerait bien moins de sympathie chez le lecteur.

$L^{\prime}$ une des ressemblances les plus frappantes entre ces deux livres est I'emploi du cadre pour révéler' la transformation de l'héroĩne. Certes, il y a chez chaque femme une reconnaissance de sa fatalits commune et par conséquent, une détérioration de l'esprit en face de cette dure fatalité. Et dans chaque oeuvre le milieu change au fur et à mesure que l'état d'âme de I'héroine se transforme. Dans L'Assommoir, le comble du bonheur de Gervaise est symbolisé par la boutique bleue, un petit monde bienheureux où tout sent la fraîcheur et la propreté. Mais comme les choses prennent un mauvais tour, le milieu de Gervaise se déteriore petit à petit. La boutique devient progressivement laide, sinon dégoûtante. Mais la boutique est encore trop belle pour servir de cadre à la chute de l'héroĩne et la famille déménage en des lieux plus misérables. C'est une dégradation commune de 1 'environnement et de son état d'âme. Par contre, dans Tess, c'est la nature qui se transforme pour augmenter $\bar{l}^{\prime}$ impression de la détérioration physique et mentale de la jeune femme. La maison de son père devenue hostile lui pèse, et en la quittant, elle se sent libérée. Avant le mariage fatal, Tess est inondée d'espoir et de soleil. Mais peu avant la scène tragique où elle se confesse à son mari, le cadre prévient le lecteur: "Out-of-doors there began noises as of silk smoothly 
rubbed; the restful dead leaves of the preceding autumn were stirred to irritated ressurection, and whirled about unwillingly, and tapped against the shutters. It soon began to rain " (pp.192-193). Les feuilles mortes peuvent parfaitement représenter l'état d'âme de Tess: comme elles, elle n'éprouve qu'une résurrection temporaire, et elle est bousculée contre son gré.

Comment change l'état d'âme d'une telle héroĩne? On voit Tess se battre furieusement contre sa destinée, cherchant toujours le bonheur honorable. Masis enfin aucune de ses qualités de femme honnête ne 1'aide. Gervaise "caressait...un bonheur parfait" qu'elle n'atteint jamais. Après peu de temps 1'héroĩne se rend compte de l'inutilité de ses efforts. sans jamais renoncer à l'espoir. Il en résulte que Tess et Gervaise finissent par saisir tout petit bonheur qui se présente. Comme 1'écrit Zola, "son besoin d'être heureuse lui faisait tirer tout le bonheur possible de ses embêtements " (p.815). Tess ne peut plus que se demander "why she was doomed to be seen and coveted that day by the wrong man and not... the right and desired one in all respects " (p.33). Par conséquent, les deux femmes, confuses, cherchant le bonheur honnête, n'éprouvent qu'échecs en amour. Elles tâchent d'être honnêtes femmes même lorsque tout le monde les méprise. Leur existence même est menacée au moment où le sentiment de leur fatalité pénètre dans le coeur de chacune.

Et Tess et Gervaise subissent par conséquent une fin honteuse. C'était tout à fait inévitable. Tess ayant finalement touché au bonheur qu'elle cherchait, tue un homme, non sans justification, mais c'est par cet acte qu'elle paraît obéir aux lois fatales de sa destinée. E1le est chassée, condamnée, pendue. Et Gervaise meurt de faim, complètement écoeurée par la vie. C'était pour toutes les deux, assurément, "comme un coup d'assommoir:"

On voit en outre que Zola et Hardy se font une idée similaire de Dieu. Ils ne renient pas son existence, mais ils affirment que Dieu ne se mêle pas de ces affaires ordonnées. Dieu n'intervient pas. Tout de 
même, on ressent la désapprobation des auteurs envers un dieu qui aurait laissé les gens sans secours. Gervaise dit que s'il y a un dieu, "il arrange drôlement les choses." En fait, il les abandonne.

Gervaise et Tess sont de bons exemples de la pensée identique chez deux créateurs. Ces femmes honnêtes et aimables sont toujours ballottées par une destinée capricieuse qui n'a aucun lien avec Dieu. Leurs milieux changent pendant que leurs esprits se détériorent, car leurs vies ne sont plus qu'un lent acheminement vers une fin honteuse.

\section{Sources}

Hardy, Thomas. Tess of the D'Urbervilles. Boston: Houghton Mifflin, 1960.

Zola, Emile,. Oeuvres Complètes. t. III. Paris: Cercle du Livre Précieux, 1962.

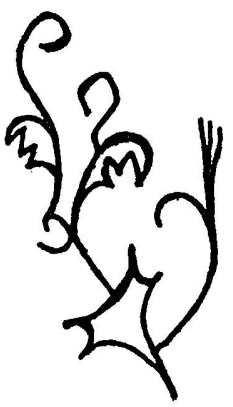




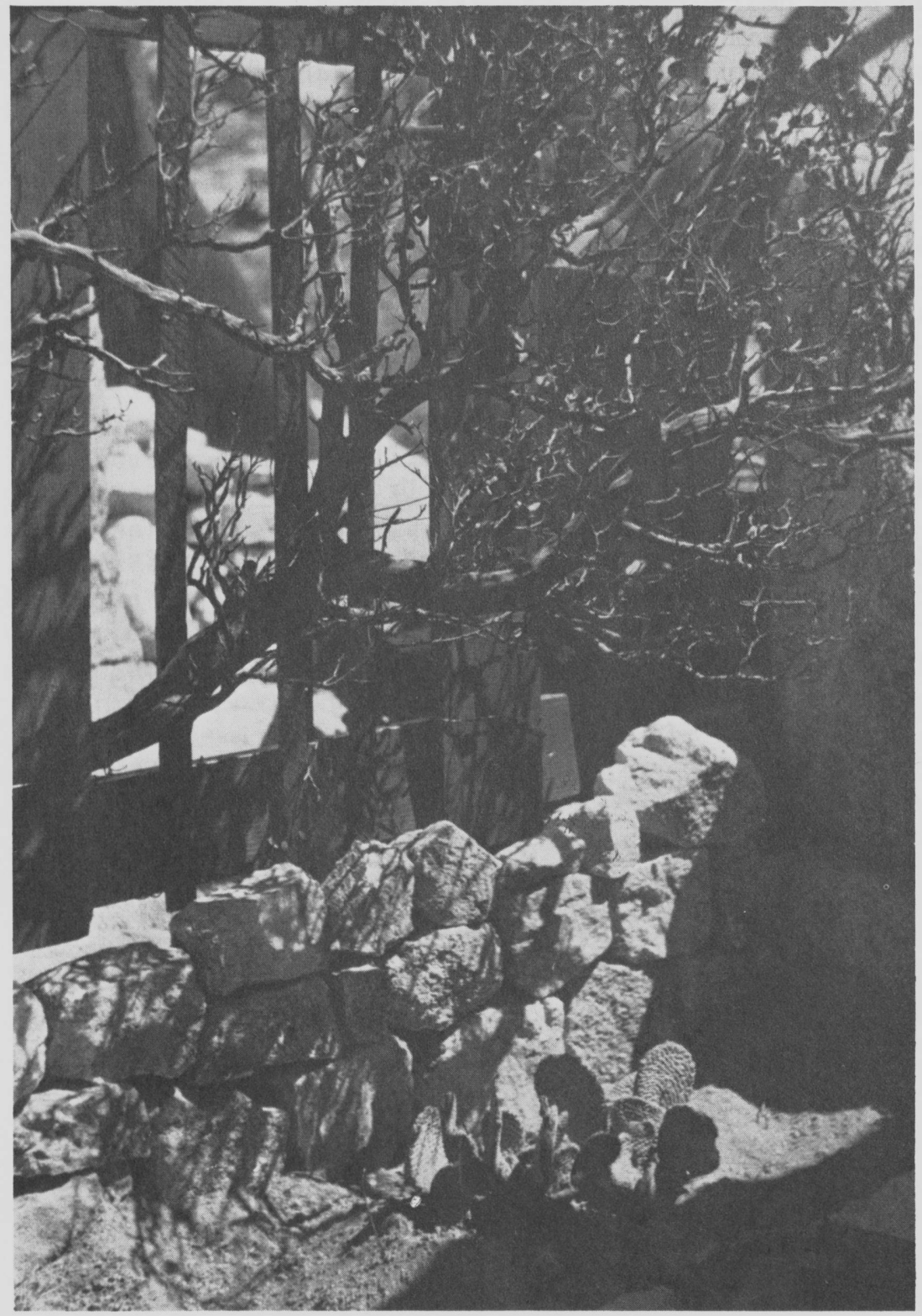

